\title{
III. Die Capitelindices
}

In den Handschriften sind die Kephalaia vor jedem Buche zusammengestellt. Die allgemeinen Beobachtungen von Ed. Schwartz (Eusebius KG III, S. CL ff) über die Kephalaia der KG des Eusebius und seine Darlegung der Tatsache, daß diese Kephalaia auf den Autor selbst zurückgehen, passen genau ebenso auf die KG des Theodoret, und ich kann es mir ersparen, mich hier über den Gegenstand weiter auszulassen. Die Überlieferung des Theodoret bestätigt gleichfalls die Ansicht von Schwartz, daß ursprünglich die Kephalaia nicht innerhalb des Textes am Rande wiedergegeben waren. Unter den alten Handschriften tun dies nur $\mathrm{L}$ und beim fünften Buch $\mathrm{V}$ ziemlich regelmäßig.

In allen HSS sind die Kephalaia mit Zahlen bezeichnet und die Zahlen am Rande der Abschnitte des Textes selbst wiederholt. Ich möchte nicht mit Bestimmtheit zu versichern wagen, wie es Schwartz tut, daß dies nicht ursprünglich ist. Einmal verlieren ohne solche Verweisungszahlen die Übersichten zum großen Teil ihren Nutzen. Sodann beobachten wir, daß die Verfasser der ältesten Excerpte, z. B. Cassiodor und die Syrer ein Capitel oder eine Reihe von Capiteln genau in der Folge ausziehen, welche die Zahlen am Rande unsrer besten Überlieferung anzeigen. Mir scheint daher, daß sie die Kephalaia an der Spitze des Buches zu Rate zogen (den Titel geben sie oft an der Spitze wieder z. B. Vaticanus syriac. S. $303 \mathrm{ff}$ ) und dann die entsprechenden Zahlen am Rande des Textes aufsuchten. Selbstverständlich waren die Übersichten und die Zahlen in hohem Maße Änderungen ausgesetzt, und fast auf jeder Zeile machen sich die Absonderungen von Gruppen bemerkbar, die meine Einteilung der Handschriften bestätigen.

Praktische Gründe verboten mir, die Zahlen der Capitel zu ändern, welche, abgesehen von Sirmond und Noesselt, in allen Ausgaben gleich sind. Ebenso habe ich die von Gaisford eingeführte Paragrapheneinteilung beibehalten. Wenn die Capiteleinteilung der Ausgaben in Widerspruch steht mit den Kephalaia und mit den Zahlen der guten Handschriften, habe ich am Rande des Textes die von den Handschriften gebotene Zahl zugefügt.

\section{Die Handschrift des Nicephorus}

Die Kirchengeschichte des Nicephorus Callistus ist in ihrem größten Teile nur eine Aneinanderreihung oder ein Gemisch von Stücken, die er aus seinen Vorgängern entlehnt hat. Die Herausgeber des Eusebius haben es für überflüssig gehalten, sich bei der Aufstellung ihres Textes 